\title{
As novas formas urbanas: estudos do movimento na definição das urbes da região da Serra Gaúcha (RS)
}

\section{The New Urban Forms: Studies of Urban movements and its impact on Urbes Definition in the Serra Gaúcha (RS, Brazil).}

\section{Pedro de Alcântara Bittencout César, Eurico de Oliveira Santos}

\section{RESUMO}

Estuda-se a relação entre a movimentação turística no nordeste gaúcho (fluxos), com as formações urbanas (fixos). A pesquisa, de caráter heurístico, busca o reconhecimento histórico das condições de assentamento no Brasil e, especificamente, na Serra Gaúcha e Região das Hortênsias. Objetiva-se identificar os valores constituintes da formação urbana nas cidades de Gramado (RS) e Caxias do Sul (RS), como natureza idealizadora, aos assentamentos de colônias migratórias das cidades estudadas, até a sua constituição na urbanização turística. $\mathrm{Na}$ adoção de uma perspectiva weberiana, realiza-se pesquisa exploratória acompanhada de inventário dos equipamentos urbanos nas cidades de Caxias do Sul (RS) e Gramados (RS). Analisa, nessas localidades, sob o enfoque da Teoria do Espaço Turístico, a distribuição de equipamentos e atrativos turísticos. Com base em tais levantamentos, realiza-se, como procedimento metodológico, pesquisa Histórico-Genética de suas formações urbanas. Primeiramente, definem-se os conceitos de fluxos e fixos na elaboração dos objetos do espaço. Por conseguinte, fundamenta-se o estudo das movimentações, principalmente de pessoas, na definição das formas urbanas. Fluxos que, a cada novo momento, estabelecem novos fixos, definindo parte das estruturas urbanas atuais dos municípios analisados.

PALAVRAS-CHAVE: Urbanização; Turismo; Urbanização Turística; Formas Urbanas; Nordeste do Rio Grande do Sul.

\begin{abstract}
This study presents the link between the movement of people (people flows), mostly tourists, in urban formations (fixed). This heuristic research, seeks an historical recognition of the settlement conditions in Brazil, specifically in the Serra Gaúcha, at Região das Hortênsias. The constituent values of Brazilian urban formation have been identified since the Colonial Period; for instance, we have the creation of an idealized nature to the settlement of migratory colonies in the cities which we focused this research. Adopting a Weberian perspective, an exploratory research was carried out together with the inventory of urban equipment in the cities of Caxias do Sul (RS) and Gramado (RS). Also, we have analyzed, from the Theory of Tourism point of view, the distribution of these equipment and tourist attractions into the aforementioned cities. Thus, based on these surveys, we carried out a Historical-Genetic research on their urban formations. For this, we have defined the concepts of flows and fixed in the development of tourism space objects. In addition, we have based the study of movement, especially people flows, on the definition of urban forms. These flows, at every new moment, have been establishing new "fixed" that, if in combination with the "flows", might define the current urban structures of the studied cities.
\end{abstract}

KEYWORDS: Urbanization; Tourism; Tourist Urbanization; Urban Forms; Northeast of Rio Grande do Sul. 


\section{Introdução}

A formação urbana no Brasil é objeto de empenho científico (REIS FILHO, 1968, p.15). Seu interesse perpassa o reconhecimento de duas relações engendradas e independentes: das redes e dos núcleos. Neles, identificam-se condições que definem as origens sociais do processo de urbanização no país.

Relaciona-se, constantemente, a forma urbana com "a estrutura espacial interna da cidade capitalista" (SOJA, 1993, p.221). Nessa condição, nota-se que sua constituição se reelabora a cada formação socioeconômica estabelecida, recriando e transformando alterações espaciais, sociais e econômicas. Reporta-se à cidade por uma relação urbana historicamente definida. Na pesquisa, estende-se o olhar à dimensão metodológica e compreender o fenômeno urbano pela ação de seus sujeitos. Desta forma, partindo de um projeto mais amplo de reconhecimento da região da Serra gaúcha e Região das Hortênsias, analisa-se parte da atuação dos sistemas de ação (movimento) no assentamento espacial.

No estudo das localidades e seus estatutos na definição do território constituído, observa-se que, marcantemente, são definidos as lógicas dos sistemas de objetos espaciais. Historicamente, o espaço se define pelos fixos; que tem como pressuposto a existência de pares dialéticos entre fluxos e fixos, associado, principalmente, à movimentação produtiva e de pessoas. Analisa-se Caxias do Sul e Gramado, na região nordeste do Estado do Rio Grande do Sul. Caxias do Sul caracteriza-se como o segundo maior polo metal mecânico do Brasil (BORBA, 2003), o que se contrapõe com Gramado, um dos principais centros receptores de turistas do país (TOMAZZONI, 2007).

A relação de movimentação turística na configuração do urbano posiciona-se como uma das diversas maneiras necessárias para o entendimento regional. Os fluxos, e toda a sua característica efêmera, definem territorialidades, territórios e estruturas urbanas. Assim, posiciona-se o turismo como uma das muitas formas de configuração territorial.

\section{Questão de método}

Desenvolve nesta pesquisa por abordagens metodológicas distintas. Primeiramente, realiza-se um levantamento de fundamentação heurística, buscando, com a base teórica, refletir sobre as constituições formação urbana analisada. Assim, pesquisam-se as formações sócio-espaciais, dando ênfase às urbes do nordeste do Estado do Rio Grande do Sul.

Define-se o campo conceitual para o reconhecimento e delimitação da área de pesquisa. Inicia-se esse estudo por fontes históricas. Seguidamente, realiza-se pesquisa exploratória da região. Levanta-se o local, para o entendimento dos equipamentos urbanos e turísticos, na sua formação. Essa pesquisa, desenvolvida em um centro de Estudos Urbanos universitário, envolveu diversos trabalhos e pesquisadores de iniciação científica, o que viabilizou o levantamento das informações. Finaliza-se com o entendimento das diversas formas urbanas incorporadas ao longo do processo de consolidação das cidades, visto que, se trata de um estudo constituído a partir do método Histórico-Genético, 
analisam-se as estruturas, "causadas pelo desenvolvimento ulterior (interior ou exterior) e por sua subordinação às estruturas de conjunto" (LEFEBVRE, 1986, p.173). Parte-se da relação do homem em movimento, que, ao penetrar no interior do Brasil, caracteriza uma condição efêmera,resultando na sua fixação e formação urbana. Tal questão sintetiza-se na transformação das inúmeras relações de fluxos. Elaboram-se formas que tendem a se adaptar, a cada momento, a novas relações de transformações causadas pelo fluxo de pessoas e objetos.

$\mathrm{Na}$ definição do campo epistemológico, aproxima-se de Lepetit (2001). Dessa maneira, estuda-se na localidade a Arquitetura, a Geografia e a História (urbana) como princípios de variação de escala. Assim, suas abordagens, são recursos complexos desta reconfiguração. Esses são "camadas superpostas da realidade social" (SALGUEIRO, 2001, p.23). Nelas, a sociedade deve ser vista como uma categoria da prática social e não como adereços das relações de produção e de representação.

Adotam-se os conceitos weberianos de formação urbana. Desse modo, entende-se que as densidades demográficas, as profissões urbanas, a economia urbana, a força militar, independência político-administrativa determinam suas configurações (WEBER, 1979). Assim, parte-se da questão norteadora: as formas urbanas adaptam-se a partir das condições de produção e movimento das sociedades. Neste sentido, esta pesquisa objetiva compreender essas transformações morfológicas. Entretanto, espera-se, por uma base estruturalista, dialogar com as relações temporais e sociais, apoiando-se na Teoria do Espaço Turístico de Boullón (2002).

No reconhecimento das relações sociais no espaço, busca-se compreender a apropriação e definição dos territórios das localidades estudadas. Retrata-se, fundamentalmente, uma condição de consumo espacial, embasada em Bourdieu (2003) e suas tipologias diversas do indivíduo. Nelas, relacionam-se o sujeito e espaço por uma dimensão cotidiana (SIMMEL, 2006), para no entendimento dos atores, reconhecer as novas formas de apropriação no espaço.

\section{Reconhecimento das bases teóricas}

São características da cidade moderna: a economia em movimento e a invenção das práticas funcionalistas (LEPETIT, 2001, p.51). Sabe-se que cidade e sociedade são categorias distintas. Porém, a questão social e a questão urbana se sobrepõem com naturalidade. A cidade se realiza e se materializa, ao ser ela feita de pedra e cimento. Assim, o estudo da cidade "dispõe de uma materialidade, [que] constitui uma forma que se estende no espaço" (LEPETIT, 2001, p.74).

Entender a formação urbana no Brasil baseia-se em duas questões distintas: A lógica presente no imaginário do colonizador e a das condicionantes locais. Assim, o colonizador, sobretudo europeu, encontra condições diversas no continente sul-americano. Estes são estatutos na formação urbana brasileira. Entretanto, o imaginário europeu define a lógica ocidental na América do Sul. Tal condição justifica o entendimento da cidade européia proposto por Benevolo (1983) em localidades distintas e distantes. Nas reflexões acerca de todo o mundo, seu recorte, é reforçando na formação urbana européia, funda- 
As novas formar urbanas: estudos do movimento na definição das urbes da região da Serra Gaúcha (RS)

da ultramar, como povos colonizados.

A pesquisa histórico-morfológica (BENEVOLO, 1983) associa o assentamento humano a algumas condições: A existência de condições físicas ambientais e suas relações espaciais; A produção agrária ou extrativista como condições específicas para sua formação; As necessidades humanas se reproduzem como necessidades sociais. Na condição cultural na América, "os mercadores europeus encontram um enorme espaço vazio, onde podem realizar novos grandes programas de colonização e de urbanização" (BENEVELO, 1983, p.469). Normalmente, esses recaem em instruções para instalações em tabuleiros retilíneos e projetados. Assim, a colonização espanhola elabora suas cidades sob as leis urbanísticas de 1573, que pré-estabeleciam essas condições. Define-se novas formas e funções urbanas.

O Urbano pode ser entendido como "uma forma especial de ocupação do espaço por uma população, a saber, o aglomerado resultante de uma forte concentração e de uma densidade relativamente alta, tendo como correlato previsível uma diferenciação funcional e social maior" (CASTELLS, 2000, p.40). Nele, os processos de urbanização e a cultura urbana apresentam-se em constante contradição, e pode ser compreendido como uma dimensão. Assim, seu conteúdo social relaciona à Cidade, como primeira natureza, embora, seu valor, hoje, pode definir como uma "utopia libertária" (CASTELLS, 2000, p.145). A estrutura da cidade não se restringe a sua morfologia, "ele é suporte de um modo de vida mais ou menos intenso ou degradado: a sociedade urbana" (LEFEBVRE, 2001, p.11). A cidade, materialidade, tem o urbano ou sociedade urbana como abstração de uma "prática social em marcha" (LEFEBVRE, 2004, p.28). Nela, definem-se tipos de urbanização, com as estruturas urbanas estabelecidas e diferenciadas nas formas e funções. No seu processo formador, elementos são introduzidos - como o automóvel que configuram novos valores e funções nas ruas, apropriando e expropriando, destruindo a vida social e conferindo valores de organização e de consumo.

A análise do fenômeno urbano, assim como nas relações sociais é complexa. Nela, envolvem-se estruturas visíveis e invisíveis em que cada novo avanço implica novas interpretações. Desta maneira, aborda-se "o fenômeno urbano pelas propriedades formais do espaço antes de estudar as contradições do espaço e os seus conteúdos, ou seja, de empregar o método dialético" (LEFEBVRE, 2004, p.59). Na definição das formas espera-se reconhecer as funções e estruturas para proceder à análise do fenômeno urbano nas centralidades e nos movimentos.

\section{Definição de fluxos e fixos na formação espacial}

A cidade e o urbano estão relacionados a um determinado Modo de Produção (MORAES, 2002). Nele se "exprime toda uma concepção geral da produção das relações sociais, quer dizer, em definitivo, uma teoria da mudança social, uma teoria da revolução" (CASTELLS, 1983, p.145), com um sistema de valores, normas e relações sociais. Entretanto, encontra uma reação de produção na centralidade, no adensamento, na densidade, que são as suas essências.

A respeito de formas, e a sua relação com a lógica social e o seu comportamento, 
Castells (1983, p.156) pontua sua existência, particularmente "com respeito à vida social local, em particular com referência aos vizinhos", e afirma que unidades de vizinhança reforçam o sentimento de filiação espacial.

O espaço social é definido como de produção social (LEFÈBVRE, 1974, p.15). Este pode ser pensado pelos componentes "geográficos, econômicos, demográficos, sociológicos, ecológicos, comerciais, nacionais, continentais, mundiais” (SANTOS, 1997, p.24). Um valor marcante refere-se à formação de circuitos superiores e inferiores da economia. Relação de uma constante contradição da estrutura capitalista (SANTOS, 2004). Esta pode justificar as atividades e as relações espaciais que engendram com os econômicos e sociais.

Porém, pensa-se no estatuto do espaço como uma organização de relações diversas, envolvendo formas, funções, estruturas e processos que definem a totalidade do espaço. A forma evidência os aspectos visuais, a exterioridade do espaço (ou um dos aspectos da realidade). A função, o papel do objeto criado (como o trabalho e o lazer) ou mesmo o consumo de determinados locais pelo visitante. A relação restrita entre forma e função desenvolve-se, diretamente, tendo um cuidado com seu caráter funcionalista, que retira elementos de uma realidade histórica e suas características sócio-econômicas.

A estrutura não apresenta uma exterioridade imediata, representando a interrelação dos objetos, por meio da natureza social e econômica da sociedade, e o processo que remete ao seu movimento temporal. Esta categoria se elabora por uma constante transformação, evoluindo partir de um dos três princípios: as ações externas, responsáveis pela evolução do sistema; o intercâmbio entre subestruturas, capazes de evolução própria, e a evolução particular de cada elemento isoladamente (SANTOS, 1985, p.17). Afinal, "quem diz cultura ou civilização diz formas e processos e diz conteúdos, dos quais é certo que nem sempre podemos destacar ou desgrudar as formas e os processos, segundo o desejo de Simmel, sem destruir a vida do conjunto ou totalidade" (FREYRE, 1973, p.141).

As estruturas combinam relações estáticas e em movimento. Tal condição permite o seu entendimento por fluxos e fixos. Dessa maneira,

cada lugar, ademais, tem, a cada momento, um papel próprio no processo produtivo. Este, como se sabe, é formado de produção propriamente dita, circulação, distribuição e consumo. (...) Como os circuitos produtivos se dão, no espaço, de forma desagregada embora, não desarticulada, a importância que cada um daqueles processos tem, a cada momento histórico e para cada particular, ajuda a compreender a organização do espaço (SANTOS, 1985, p.3).

O espaço se realiza por uma constante dialética entre conjuntos de fixos e fluxos. Objetos e ações se interagem definindo realidades espaciais, como as formas urbanas. Nelas, o homem, por toda a sua historia, determina fluxos diversos. Movimentação e fixação definem as formações dos assentamentos. Urbes são constituídas por interesses de 
As novas formar urbanas: estudos do movimento na definição das urbes da região da Serra Gaúcha (RS)

grupos em fluxos, e assim, constituem estruturas fixas. Essas, por natureza, têm seus valores definidos por fixos, ou seja, objetos distribuídos no espaço.

Inicialmente, na formação urbana, novos povos são transplantados. Assim, novos fluxos se estabelecem, penetrando no continente americano. A necessidade de transformação da natureza inicial, faz apropriar o espaço. Atualmente, a urbanização turística (MULLINS, 1991; CESAR, 2010)

\section{Especificidade do objeto de estudo}

Com o fim do período colonial, o país se envolve com os grandes fluxos internacionais. A abertura dos portos oficializa a vinda de diversos grupos étnicos. Tal questão possibilita um maior intercâmbio de pessoas, produtos e idéias.

A formação de áreas urbanas e rurais associadas à fluxos migratórios tem tipologias definidas, principalmente, nas regiões sul e sudeste do Brasil. Assim, a Lei 514 de 12 de outubro de 1848 define novos usos a áreas devolutas, possibilitando sua inserção com a agricultura familiar do estrangeiro (DIÉGUES JUNIOR, 1964). No norte e nordeste, a presença da estrutura agrária do grande latifúndio, que predomina, inviabiliza novas formas urbanas.

No Rio Grande do Sul, entre os anos de 1874 e 1876, criam-se as colônias de Caxias, Conde D'Eu e Dona Isabel. Essas são regidas pelo Decreto 1318, de 30 de janeiro de 1885, que regulamenta a Lei de Terras de 1850. Dessa maneira, o governo estimulou a vinda de imigrantes europeus que pudessem instalar na região, beneficiados pela referida lei, e permitindo a aquisição de propriedades por estrangeiros (DE BONI, 1983). Os imigrantes italianos acompanham os projetos já exitosos da migração alemã, ocupando áreas devolutas do nordeste deste Estado(no momento Província), e transformando em regiões produtivas. A política de colonização implantar, nessa região, núcleos coloniais com a finalidade de desenvolver uma agricultura marcada pela policultura, que abastece a Província e, ao mesmo tempo, dispor de mão-de-obra especializada. Estabelece-se uma nova paisagem cultural.

O regime de pequena propriedade caracterizou originalmente os núcleos assim constituídos - de alemães, italianos, poloneses, ou mistos, estes, aliás, raros - dando um sistema de organização econômica que contrastava com o regime de grande propriedade da colonização portuguesa (DIÉGUES JUNIOR,1964, p.70).

O nordeste gaúcho se caracteriza como área de imigração. Na região de Caxias do Sul predomina a formação espacial pela migração italiana, em contraponto com a área de Gramado, de influência alemã. Hoje, essas regiões e seus respectivos municípios, têm um forte apelo na questão da movimentação de turistas, embasada nos valores étnicos dessas culturas europeias.

$\mathrm{Na}$ área, tem-se em sua tipologia de assentamento inicial, o reconhecimento da 
propriedade privada nas transformações do uso do solo para o proprietário privado. Assim, com rara exceção, o imigrante é agente da privatização e do parcelamento do espaço rural e urbano. Sua formação, com indicadores econômicos exitosos, define toda uma condição de reprodução espacial. Nesse sentido, verifica-se a dificuldade de formação de bolsões fundiários por parte do poder público, o que torna essa área, provavelmente, um dos espaços mais privatizados do país. O território se caracteriza pela existência do proprietário típico, detentor dos modos de produção.

Atualmente, os descendentes do imigrante detêm a reprodução socioeconômica da região. Entretanto, esse êxito econômico determina duas questões: A formação de concentração fundiária típica e a criação de zonas de atração de novos, e distintos, grupos sociais. O crescimento industrial define novos ciclos de crescimento econômico e migratório. Esses, oriundos, fundamentalmente, de outras regiões deste estado e do país, não encontram espaços vazios para ocupar. Assim, esta cidade de porte médio tem uma história marcada pela industrialização desde a sua ocupação inicial no século XIX.

O nordeste gaúcho se caracteriza por uma formação econômica em diversas etapas. Inicialmente, por atividades agrícolas e extrativas seguidas por um intenso comércio intra-regional, que propiciou a presença de atividades manufatureiras e, mais tarde industriais, estruturadas pela expansão de suas oficinas e pequenas indústrias (HERÉDIA, 1997). Sua economia, marcada por características industriais, expandiu-se no período das guerras mundiais e na metade do século XX, no governo do presidente Juscelino Kubitschek (JK). Assim, seu perfil tradicional se alterou para um perfil de indústrias dinâmicas, voltadas para o setor secundário, na área das indústrias metalúrgicas, mecânicas e elétricas. Nos anos noventa, modernizou seu parque industrial com a introdução de novas tecnologias que permitiram alterar o modelo de produção fordista para o modelo mais contemporâneo, racional e flexível. Associado ao desenvolvimento industrial está um crescente e desordenado processo de urbanização com o conseqüente surgimento de núcleos originados de ocupações irregulares. Neste período, definem-se novas perspectivas nos setores de serviços e, principalmente no turismo.

No município Caxias do Sul, o turismo se sustenta em três questões: como Centro de Distribuição do visitante pela região, com um apelo na visitação a roteiros de produção vinícola e no turismo de compras e negócios (POLONI, 2010). Os equipamentos e serviços turísticos estão localizados, predominantemente, no centro da cidade. Tal condição se justifica, principalmente, ao observar que a força de atração ao município está mais relacionada às indústrias do setor metal-metalúrgico e à condição de cidade sede regional. Essas referências estabelecem a visitação a Caxias do Sul.

Quando analisados os atrativos, os equipamentos e a infraestrutura turística de Caxias do Sul, partindo da localização desses elementos, foram delimitados os mais significativos (BOULLÓN, 2002). A aproximação dos equipamentos turísticos, forma naturalmente, agrupamentos. Vê-se um eixo principal na Av. Júlio de Castilhos, partindo da Praça Dante Alighieri. Verifica-se, uma predominância dos equipamentos urbanos e turísticos na área central, notadamente, no entorno da praça da Igreja Matriz (Praça Dante). A área próxima dos pavilhões da Festa da Uva e ao campus da Cidade Universitária apresenta uma concentração menor. Os demais bairros da cidade se mostram bastante desprovidos 
de atrativos. Nota-se também que os atrativos são em menor quantidade que os equipamentos turísticos (Figura 1).

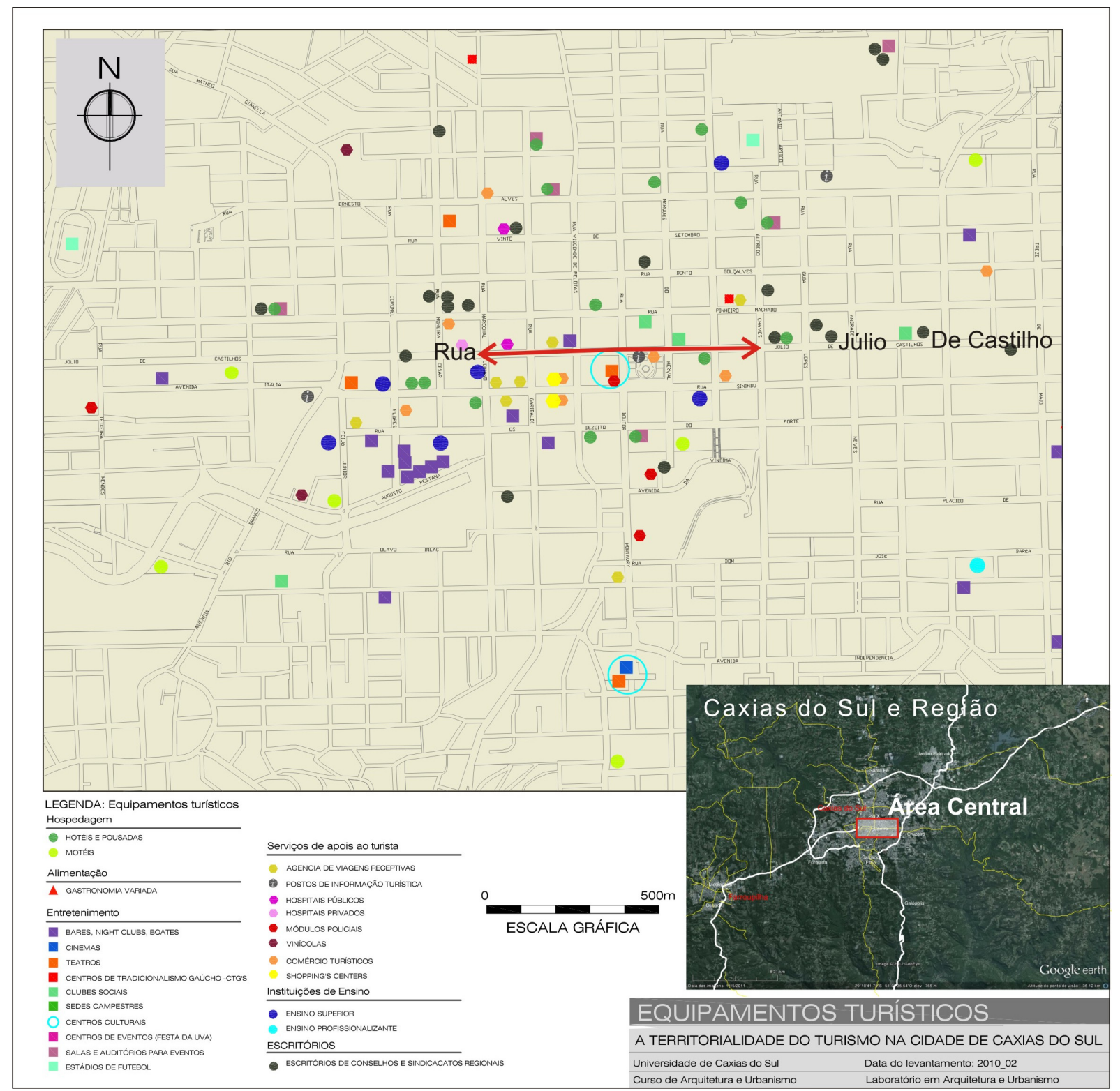

Figura 1: Área central de Caxias do Sul. Fonte: Plano Diretor, 2007. Adaptada pelo autor. Figure 1: Central area of Caxias do Sul. Source: Master Plan, 2007. Adapted by the author.

A Teoria do Espaço Turístico de Boullón (2002) se mostrou supra-regional, perante as classificações do autor quanto à superfície de abrangência, que resultariam na divisão territorial em diversas categorias. Destaca-se Caxias do Sul como Centro de Escalas. Esses são locais de escala entre conexões da rede de transporte, em 
que a permanência do turista é curta, de até 24 horas, e geralmente apresentam maior quantidade de equipamentos turísticos do que atrativos. A cidade parece ajustarse a esta classificação, pois, pelo seu porte, apresenta uma Estação Rodoviária de uso regional e um Aeroporto com vôos regulares. Destaca-se que o município está localizado entre os três principais destinos turístico do Estado, que são Porto Alegre, Bento Gonçalves e Gramado (TOMAZZONI, 2007), e oferece grande quantidade de equipamentos e infra-estrutura turística, que serve de apoio a estes centros indutores de turismo.

Gramado apresenta outra reprodução espacial em virtude da dimensão da visitação turística. Definida como Centro Turístico (ROSA, 2011), percebe-se que a maior concentração dos atrativos fica na parte leste do município, que faz divisa com o município de Canela (Figura 2). As duas avenidas, Borges de Medeiros e das Hortênsias, são as que possuem as maiores aglomerações de serviços. A hotelaria é bem distribuída, mas prevalece à aproximação com o município de Canela (RS) e com os atrativos. Os equipamentos gastronômicos se instalam nas proximidades da rede hoteleira de forma a atrair os visitantes para o consumo de seus produtos. Essa proximidade viabiliza o turismo.

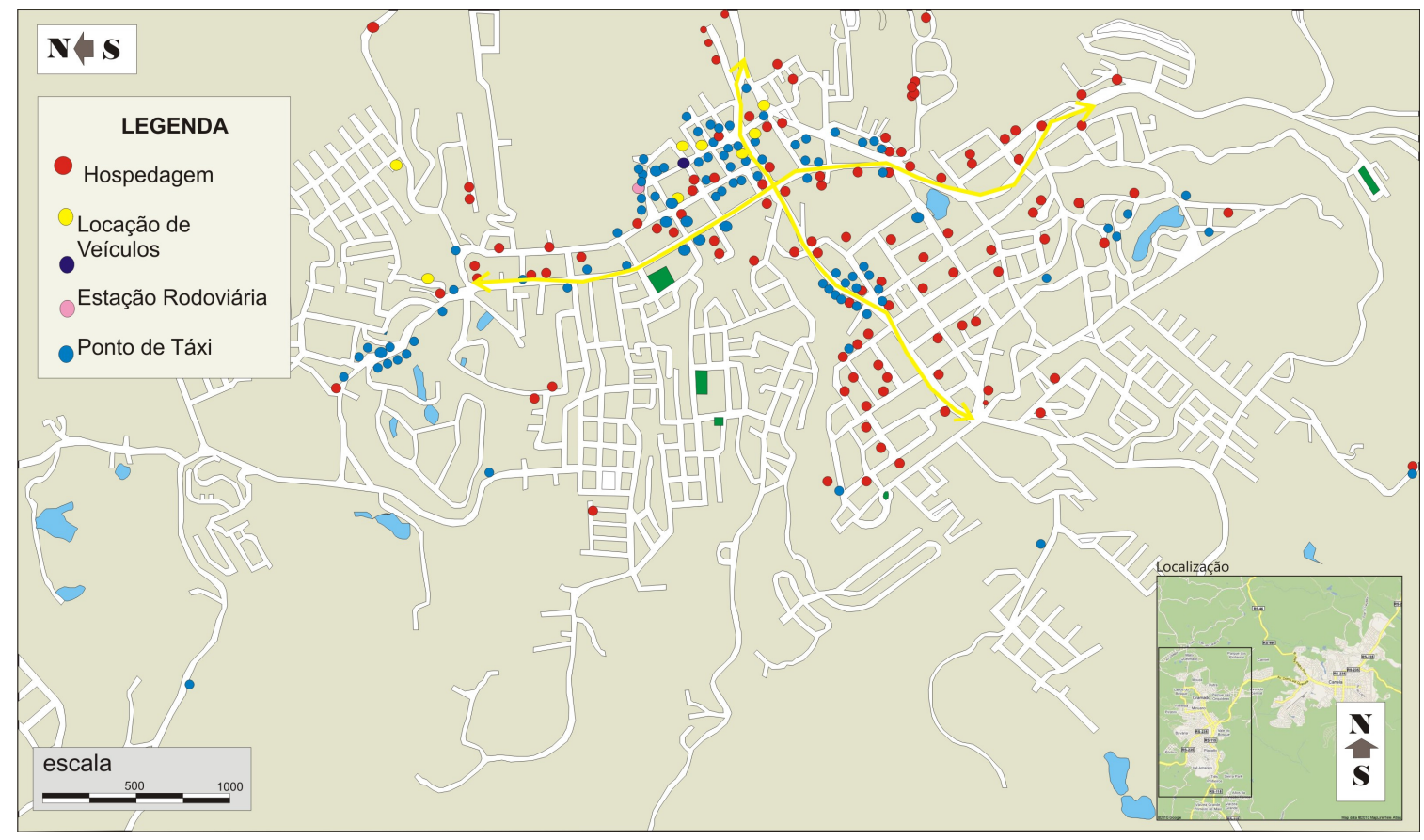

Figura 2: Área central de Gramado. Fonte: Autoria própria.

Figure 2: Central area of Gramado. Source: Author own.

Observa-se, no entanto, que existe uma preocupação urbanística em não avançar a rede gastronômica mesmo que próxima aos hotéis, na parte oeste do município. 
Esta distribuição espacial evita a descaracterização das áreas de convívio cotidiano dos moradores. Para o turista, esta configuração facilita o direcionamento ao centro da cidade, onde pode ser atraído a efetuar suas compras no comércio local. As agências bancárias se agrupam também na área central urbana, em direção a Canela. Essas configurações evidenciam, no município, a delimitação de áreas de destino ao turismo, consumo e eventos.

\section{Considerações finais}

A sociedade está em constante movimento. Essas ações proporcionam, a todo o momento, novas configurações espaciais. Raramente, estuda-se, no urbanismo, o homem por esta natureza sedentária. O recorte se faz no repouso, no assentamento, nos dias atuais, no entanto, demanda-se refletir à sociedade por suas condições de fluir.

Nesse recorte espacial, inicialmente, o imigrante atravessa um oceano para defini-las, transplantando, impondo e condicionando suas estruturas culturais e sociais. Nelas, as bases físico-territoriais materializam-se os interesses diversos de formação de áreas urbanas e rurais. Valores distintos são definidos considerando os fluxos e definindo as bases da atratividade para a formação da urbanização turística. A expansão da urbanização das cidades é um dos principais fatores para as transformações urbanas. A região do nordeste gaúcho, incluindo, principalmente, a Região das Hortênsias (Gramado), possui uma forte caracterização territorial em virtude da formação de áreas para o turista. Esta situação se justifica, em grande parte, pelo papel econômico que o setor representa. O turismo nesta região se consolida. A acessibilidade por meio das diversas vias de acesso com sinalização turística adequada demonstra essas novas formações urbanas. Nesses locais, configura-se grande número de atrativos culturais, principalmente, com apelo de consumo.

No local, diversas formas de produção são elaboradas. Muitas, ou todas, com a presença de circulações distintas que configuram a base da formação urbana das cidades. Seu reconhecimento se torna necessário para o entendimento da totalidade da localidade.

\section{Referências bibliográficas}

BENEVELO, L. História da cidade. São Paulo: Perspectiva, 1983.

BOULLÓN, R.C. Planejamento do espaço turístico. Bauru, SP: Edusc, 2002.

BOURDIEU, P. A economia das trocas simbólicas. 5eㄹ. São Paulo: Perspectiva, 2003.

CASTELLS, M. A questão urbana. São Paulo: Paz e terra, 2000.

BORBA, S.V. Indústria e estruturação do espaço regional: agentes da estruturação espacial da Aglomeração Urbana do Nordeste do Rio Grande do Sul. Porto Alegre: 
Tese (doutorado). PPG Sociologia-UFRGS, 2003.

CÉSAR, P.A.B. Urbanização Turística: esboço para a definição de uma categoria do espaço social. Turismo em Análise. São Paulo, n.21, Ago. 2010, pp. 1-15.

DE BONI, L.A. A Itália e o Rio grande do Sul IV: Relatório de autoridades italianas sobre a colonização em terras gaúchas. Caxias do Sul: EST e EdUCS, 1983.

DIÉGUES JUNIOR, M. Imigração, urbanização, industrialização: estudos sobre alguns aspectos da contribuição cultural do imigrante no Brasil. Rio de Janeiro: InepMec, 1964.

FREYRE, G. Sociologia: introdução ao estudo dos seus princípios. $5^{\circ}$ Ed. Livraria José Olympio e INL/MEC, Tomo I, Brasília: 1973.

HERÉDIA, V.B. Processos de industrialização da zona colonial italiana. Caxias do Sul: Educs, 1997.

LEFEBVRE, H. La production d'espace. Paris: Anthropos, 1974.

LEFEBVRE, H. Perspectiva da sociologia. In MARTINS, J.S. (org.). Introdução crítica à sociologia rural. São Paulo: Hucitec, 1986.

LEFEBVRE, H. O direito à cidade. São Paulo: Centauro, 2001.

LEPETIT, B. Por uma nova história urbana. São Paulo: Edusp, 2001.

MORAES, A.C.R. Ideologias geográficas: espaço, cultura e política no Brasil. 4ed. São Paulo: Hucitec, 2002.

MULLINS, P. Tourism urbanization. International Journal of Urban and Regional Research, v.15, n.3. 1991, pp.326-342.

OMEGA, N. A fisionomia da cidade colonial. In FERNANDES, F. (org.). Comunidade, sociedade no Brasil: Leituras básicas de introdução ao estado macro-sociológico do Brasil. São Paulo: Ed. Nacional e EdUSP, 1972, pp.86-94.

POLONI, F.. A territorialidade turística em Caxias do Sul. Relatório de Iniciação Cientifica. Caxias do Sul: UCS, 2010.

REIS FILHO, N.G. Contribuição ao estudo da evolução urbana do Brasil: 1550/1720. São Paulo: Pioneira, 1968.

ROSA, R. A territorialidade turística na região das Hortênsias. Relatório de Iniciação Científica. Caxias do Sul: UCS, 2011.

SANTOS, M. Espaço e método. São Paulo: Nobel, 1985.

SANTOS, M. Metamorfose do espaço habitado. 5ed. São Paulo: Hucitec, 1997.

SANTOS, M. O espaço dividido: os dois circuitos da economia urbana dos paises subdesenvolvidos. 2ed. São Paulo: Edusp, 2004.

SIMMEL, G. Questões fundamentais da sociologia: individuo e sociedade. Rio de Janeiro: Jorge Zahar Editor, 2006. 
SOJA, E.W. Geografia pós-moderna: a reafirmação do espaço na teoria social crítica. Rio de Janeiro: Zahar, 1993.

TOMAZZONI, E.L. Turismo e desenvolvimento regional: Modelo APL aplicado à região das Hortênsias (Rio Grande do Sul-RS). São Paulo: Tese (doutorado), ECA-USP. 2007.

WEBER, M. Conceitos e categorias da cidade. In VELHO, O.G. (org.). O fenômeno urbano. 4ed. Rio de Janeiro: Zahar, 1979.

Pedro de Alcântara Bittencout César: Universidade de Caxias do Sul, Caxias do Sul, RS, Brasil.

Email: bittencourt_tur@yahoo.com.br

Link para o currículo Lattes: http://lattes.cnpq.br/0900226519393513

Eurico de Oliveira Santos: Universidade de Caxias do Sul, Caxias do Sul, RS, Brasil. Email: eurico58@terra.com.br

Link para o currículo Lattes: http://lattes.cnpq.br/7321278494223871

Data de submissão: 27 de maio de 2012

Data de recebimento de correções: 20 de novembro de 2012

Data do aceite: 20 de novembro de 2012

Avaliado anonimamente 